\title{
TINGKAT KEEKONOMIAN KEGIATAN PENAMBANGAN BATUBARA PT. CITRA TOBINDO SUKSES PERKASA BERDASARKAN METODE DISCOUNTED CASH FLOW
}

\author{
THE ECONOMIC LEVEL OF COAL MINING ACTIVITIES IN PT. CITRA \\ TOBINDO SUKSES PERKASA USING DISCOUNTED CASH FLOW METHOD
}

\author{
A.Fizarro ${ }^{1}$, Mukiat $^{2}$, Syarifudin $^{3}$ \\ 1-3 Jurusan Teknik Pertambangan, Fakultas Teknik, Universitas Sriwijaya \\ Jl. Raya Palembang-Prabumulih Km.32 Inderalaya Sumatera Selatan, Indonesia \\ e-mail: ㅁafizarro@gmail.com, ${ }^{2}$ mukiats@gmail.com, ${ }^{3}$ syarif_unsri@yahoo.com
}

\begin{abstract}
ABSTRAK
PT. Citra Tobindo Sukses Perkasa melakukan kegiatan penambangan batubara sejak tahun 2010 sampai dengan sekarang, akan tetapi pada tahun 2016 pernah berhenti produksi untuk sementara waktu dikarenakan oleh harga batubara pada saat itu berada di titik terendah. Untuk menghindari adanya perubahan-perubahan pada kondisi yang sensitif, maka perlu dilakukannya analisis keekonomian penambangan yang berada di tingkat ekonomi rendah, sedang, ataupun tinggi. Tujuan penelitian ini adalah mengetahui kelayakan ekonomi penambangan dinyatakan layak untuk dilaksanakan atau tidak berdasarkan tingkat keekonomiannya. Metode penelitian yang digunakan adalah metode discounted cash flow yang berprinsip menghitung dan menganalisis kelayakan ekonomi dengan hasil keputusan yang jelas dan konsisten berupa layak atau tidak layak untuk diimplementasikan. Hasil penelitian dari parameter investasi dinyatakan layak untuk ditambang dengan net present value (NPV) sebesar Rp 17.492.288.670,07, internal rate of return (IRR) bernilai 22,07\%, payback period (PBP) selama 3,70 tahun, present value rasio (PVR) bernilai 0,35 , gross benefit cost ratio $($ Gross $\mathrm{B} / \mathrm{C})$ bernilai 1,35 . Harga jual batubara dan biaya operasional sangat berdampak terhadap parameter ekonomi yaitu pada tingkat ekonomi tinggi dinyatakan layak untuk ditambang sedangkan pada tingkat ekonomi rendah dinyatakan tidak layak untuk ditambang berdasarkan pengaruh terhadap kelayakan investasi. Sedangkan pada Biaya kapital dan umur proyek juga mempengaruhi kelayakan ekonomi dilihat dari tingkat ekonomi yang tinggi dinyatakan layak untuk ditambang sedangkan pada tingkat ekonomi yang rendah dinyatakan masih layak untuk ditambang tetapi dengan nilai ekonomis yang rendah.
\end{abstract}

Kata kunci: Harga Batubara, Tingkat Ekonomi, Kelayakan Penambangan

\section{ABSTRACT}

PT. Citra Tobindo Sukses Perkasa has been carrying out coal mining activities from 2010 to the present, but in 2016 it had stopped production for a while because the price of coal at that time was at its lowest point. To avoid changes in sensitive conditions, it is necessary to carry out an economic analysis of mining which is at a low, medium or high economic level. The purpose of this study is to determine the economic feasibility of mining whether it is feasible or not based on its economic level. The method of research is discounted cash flow method with the principle of calculating and analyzing economic feasibility with clear and consistent decision results in the form of feasibility or unfit implementation. The results investment parameters were eligible for mining with a net present value showed that the NPV of IDR 17,492,288,670.07, an internal rate of return (IRR) of $22.07 \%$, a payback period (PBP) of 3.70 years, present value ratio (PVR) of 0.35 , and gross benefit cost ratio (Gross B/C) of 1.35. The selling price of coal and operating costs greatly affect the economic parameters, namely at a high economic level it is declared feasible to be mined while at a low economic level it is declared unfit for mining based on the influence on investment feasibility. Meanwhile, the capital cost and project life also affect economic feasibility seen from a high economic level it is declared feasible to be mined while at a low economic level it is stated that it is still feasible to be mined but with a low economic value.

Keywords: Coal Price, Economic Level, Mining Feasibility 


\section{PENDAHULUAN}

Perusahaan PT. Citra Tobindo Sukses Perkasa pernah mengalami pemberhentian produksi pada tahun 2016 dikarenakan HPB GAR 3.400 pada saat itu menuju pada titik terendah dengan angka \$16,12/ton (HPB Februari 2016). Oleh karena itu, agar dapat terus melakukan kegiatan penambangan dengan kondisi-kondisi yang sensitif perlu dilakukannya analisis mengenai keekonomian penambangan batubara menggunakan metode discounted cash flow dengan parameterparameter nilai saat ini.

Perusahaan ini merencanakan penambangan pada awal tahun 2020 dengan target produksi sebesar 400.000 ton/tahun dengan umur proyek selama lima tahun kedepan yaitu sampai dengan tahun 2024. Diharapkan pada lima tahun kedepan harga batubara akan terus stabil dan tidak sampai melewati batas kondisi sensitif yang dimiliki dari perhitungan aliran uang pada perusahaan ini.

Harga patokan batubara (HPB) berdasarkan GAR 3.400 yang dikutip dari Kepmen Energi dan Sumber Daya Mineral (ESDM) per Febuari 2020 adalah sebesar $\$ 21,12 /$ ton [1]. Di sisi lain rata-rata patokan harga pada tahun 2019 yaitu sebesar $\$ 23,49 /$ ton sedangkan pada tahun 2018 sebesar \$ 29,85/ton yang mengalami penurunan. Oleh karena itu, untuk melakukan kegiatan penambangan batubara perlu ditinjau keekonomian kegiatan tersebut berdasarkan aliran kas pada perusahaan tersebut.

Metode discounted cash flow yang digunakan menghasilkan penilaian yang lebih jelas dan konsisten dibandingkan dengan metode lainnya yaitu dengan hasil keputusan layak atau tidak layak suatu proyek untuk dilaksanakan. Parameter yang digunakan juga merupakan permodelan matematis dari risiko ketidakpastian (uncertainty) dan risiko waktu dari uang (time value of money). Sehingga dalam penelitian ini metode discounted cash flow lebih baik digunakan dalam menentukan kelayakan ekonomi. Beberapa aspek yang ditinjau sebagai penilaian antara lain Biaya kapital (biaya investasi), umur proyek, harga jual batubara, dan biaya operasional, eskalasi harga serta discount rate yang berlaku.

Aktivitas penambangan batubara pada PT. Citra Tobindo Sukses Perkasa meliputi kegiatan pemberaian dengan melakukan pembersihan tanah atas untuk selanjutnya diletakkan di disposal tanah pucuk. Tanah pucuk ini dijaga sehingga dapat dimanfaatkan pada waktu yang akan datang saat kegiatan reklamasi [2]. Pembersihan lahan tanah atas yang tidak sulit untuk digali dapat dikerjakan menggunakan alat gali mekanis, sedangkan jika material yang digali sangat sulit dikerjakan maka dapat dilakukan pemboran dan peledakan. Material ini kemudian dibawa ke waste dump atau disposal area. Selanjutnya pemuatan (loading) dilakukan untuk membawa hasil penggalian batubara kedalam dump truck [2].

Pengangkutan adalah aktivitas yang dikerjakan untuk membawa material hasil dari tempat kerja penambangan ke lokasi stockpile atau penyimpanan. Kegiatan pengangkutan tersebut berdampak pada besarnya biaya penambangan, dikarenakan profit perusahaan dipengaruhi oleh kegiatan pengangkutan tersebut. Batubara yang telah gali kemudian dimasukkan ke dump truck yang selanjutnya dibawa ke lokasi penyimpanan sementara (stockpile) batubara[3]. Perusahaan tersebut menggunakan dump truck tipe hino 500 fm 260 dalam kegiatan pengangkutan batubara.

Tujuan penelitian ini adalah menganalisis apakah kegiatan penambangan batubara pada perusahaan ini masih layak untuk dilakukan atau tidak berdasarkan keadaan ekonomis yang terjadi. Selain itu pada penelitian ini memprediksi apakah perusahaan berada di tingkat ekonomis yang rendah, sedang, ataupun tinggi, sehingga hasil dari penelitian ini dapat dimanfaatkan dalam menentukan rencana penambangan kedepan berdasarkan aspek ekonomi (finansial).

Beberapa penelitian terdahulu mengenai kelayakan ekonomi kegiatan penambangan pernah dilakukan. Ondo Immanuel S. pada tahun 2019 menganalisis kelayakan ekonomi pada kegiatan penambangan. Pada penelitian tersebut dilakukan analisis perbandingan antara harga jual batubara dan biaya operasi dengan perubahan hanya $3,5 \%,[4]$.

Penelitian terdahulu juga dilakukan oleh Rezky A. S., pada tahun 2018. Pada penelitian tersebut dilakukan analisis terhadap capital budgeting untuk kelayakan investasi usaha penambangan batubara dengan hasil perhitungan yang didapatkan hanya berdasarkan parameter NPV, dan IRR saja [5].

Penelitian terdahulu selanjutnya dilakukan oleh Martin S, pada tahun 2018 dengan menggabungkan kelayakan ekonomi berdasarkan faktor-faktor secara teknis yang terjadi yang menghasilkan alternatif pemilihan alat yang digunakan [6].

Titoe D.V., pada tahun 2018 melakukan kajian ekonomi menggunakan metode DCF pada pertambangan batubara yang dilandasi oleh harga jual dari batubara yang menurun. Penelitian tersebut hanya menggunakan tiga parameter penilaian saja yaitu NPV, IRR, dan PBP [7].

\section{METODE PENELITIAN}

Penelitian ini dilaksanakan di PT. Citra Tobindo Sukses Perkasa yang bertempat pada Kecamatan Mandiangin, Kabupaten Sarolangun, Jambi. Penelitian ini diawali dengan pengumpulan data primer berupa waktu kerja yang efektif dan konsumsi bahan bakar yang digunakan 
selama kegiatan penambangan. Data primer tersebut dapat digunakan dalam perhitungan menentukan biaya langsung yang dapat mempengaruhi tingkat produksi. Selain data primer tersebut, pada penelitian ini juga membutuhkan data sekunder berupa data jumlah alat yang digunakan, target produksi per tahun, jumlah cadangan, umur ekonomis alat, suku bunga deposito, asuransi, dan pajak, harga peralatan mekanis, harga patokan batubara, serta data harga bahan bakar, pelumas dan sebagainya. Data-data sekunder tersebut dapat digunakan dalam menghitung rincian biaya pada biaya langsung maupun biaya secara tidak langsung sehingga menghasilkan aliran kas perusahaan.

Selanjutnya jika telah mendapatkan aliran kas maka dapat dilakukan perhitungan dengan parameterparameter ekonomi seperti net present value (NPV), gross benefit cost rasio (Gross $\mathrm{B} / \mathrm{C})$, internal rate of return (IRR), present value ratio (PVR), dan payback period (PBP) [8-10].

Prinsip dari metode DCF adalah mendiskontokan cash flow yang didapatkan pada perusahaan dalam discount rate yang ditunjukkan dalam bentuk ganti rugi yang disebabkan oleh risiko ketidakpastian pada kegiatan. Selain itu juga ditunjukan dengan adanya penyusutan jumlah uang dari aliran kas yang diterima pada waktu yang akan datang disebabkan oleh perubahan nilai uang terhadap waktu $[9,10]$. Kelemahan pada metode ini terletak pada bunga yang semakin lama semakin kecil sehingga untuk perhitungan dengan umur proyek yang lama akan menghasilkan false negative atau ketidakakuratan nilai yang tinggi.

Net present value (NPV) merupakan parameter ekonomi yang mempunyai nilai akhir proyek yang telah didiskontokan sebagai kompensasi risiko dengan konsep nilai uang terhadap waktu. Kriteria ekonomi yang layak pada NPV adalah jika NPV $>0$, artinya proyek investasi baik untuk diimplementasikan. Sedangkan NPV $<0$, artinya proyek investasi tidak baik untuk diimplementasikan. Untuk menghitung dan menentukan kriteria NPV dapat menggunakan formula pada Pers. (1) berikut [8-10]:

$$
\mathrm{NPV}=\sum \frac{N B i}{(1+i)^{t}}=\sum_{i=1}^{n} N B_{i}(1+i)^{-n}=\sum \overline{B i}-\bar{C} i
$$

\section{Keterangan:}

$\mathrm{NB}=$ Keuntungan melalui faktor diskon (Rp)

$\mathrm{C}=$ Cost atau biaya di diskon (Rp)

$\mathrm{i}=$ Faktor diskon yang berlaku (\%)

$\mathrm{n} \quad=$ Waktu (tahun)

Present value ratio (PVR) merupakan parameter yang dipakai dalam mengetahui keuntungan bersih pada suatu usaha. Nilai yang dihasilkan oleh PVR dapat diartikan berapa besar keuntungan yang akan didapatkan jika dilakukannya investasi. PVR memiliki kriteria yaitu jika PVR $>0$, artinya proyek investasi baik untuk diimplementasikan. Sedangkan PVR $<0$, artinya proyek investasi tidak baik untuk diimplementasikan. Sebagai contoh jika didapatkan nilai PVR sebesar 0,35 yang artinya $35 \%$ merupakan keuntungan bersih yang akan didapatkan jika proyek ini dilaksanakan. PVR menggunakan formula Pers. (2) berikut [8-10]:

$\mathrm{PVR}=\frac{\text { Net present value }(\text { NPV })}{\text { Nilai negatif }(\text { cost })}$

Keterangan:

$\mathrm{NPV}=$ Nilai sekarang bersih $(\mathrm{Rp})$

$\mathrm{PV} \quad=$ Nilai sekarang dari nilai negatif $(\mathrm{Rp})$

Gross benefit cost rasio (Gross B/C) merupakan parameter yang dapat digunakan untuk mengetahui dan menentukan keuntungan kotor yang akan didapatkan. Biasanya Gross B/C yang dihasilkan berupa angka yang berada diatas nilai satu dengan kriteria ekonomi yang layak gross benefit cost rasio (Gross B/C) jika Gross $\mathrm{B} / \mathrm{C}>1$, artinya kegiatan untuk investasi baik untuk diimplementasikan. Sedangkan Gross B/C $<1$, artinya proyek investasi tidak baik untuk diimplementasikan. Untuk menghitung Gross B/C maka dapat menggunakan formula pada Pers. (3) berikut [8-10]:

$$
\operatorname{Gross} B / C=\frac{\sum_{i=1}^{n} B i(1+i)^{-n}}{\sum_{i=1}^{n} C_{i}(1+i)^{-n}}
$$

Keterangan:

$$
\begin{array}{ll}
\mathrm{Bi} & =\text { Keuntungan setelah diskon (Rp) } \\
\mathrm{Ci} & =\text { Total biaya setelah diskon (Rp) } \\
\mathrm{i} & =\text { Faktor diskon yang berlaku }(\%) \\
\mathrm{n} & =\text { Waktu (tahun) }
\end{array}
$$

Internal Rate of Return (IRR) yaitu parameter yang dipakai untuk menentukan laju kecepatan balik modal suatu investasi dengan memiliki marginal siku yaitu discount rate berdasarkan tingkat suku bunga suatu negara. IRR yang dihasilkan digunakan oleh para investor untuk menentukan apakah tingkat pengembaliannya tinggi atau rendah sehingga dapat dijadikan keputusan layak atau tidak dilaksanakan [2,5]. IRR memiliki 2 kriteria. Jika IRR $>$ discount rate, artinya proyek investasi baik untuk diimplementasikan. IRR < discount rate, artinya proyek investasi tidak baik untuk diimplementasikan. Perhitungan IRR dapat menggunakan formula pada Pers. (4) berikut [8-10]:

$$
\mathrm{IRR}=i_{1}+\left(i_{2}-i_{1}\right) \times \frac{N P V_{1}}{N P V_{1}-N P V_{2}}
$$

Keterangan:

$$
\begin{array}{ll}
\text { IRR } & =\text { Tingkat pengembalian }(\%) \\
\mathrm{i}_{1} & =\text { Suku bunga kesatu }(\%) \\
\mathrm{i}_{2} & =\text { Suku bunga kedua }(\%) \\
\mathrm{NPV} & =\text { Nilai sekarang bersih }(\mathrm{Rp})
\end{array}
$$


Payback period (PBP) mengacu pada perhitungan lamanya waktu untuk memulihkan atau mengembalikan biaya dari investasi yang dilakukan. PBP dapat menentukan berapa lama investasi tersebut dapat mencapai balik modal. Payback period dengan waktu rentang yang pendek lebih menarik para investor sedangkan payback period yang mempunyai rentang waktu yang panjang sangat tidak diinginkan. Perhitungan PBP menggunakan formula pada Pers. (5) berikut $[9,10]$ :

$$
P B P=T_{p-1}+\frac{\sum_{i=1}^{n} \overline{I_{i}}-\sum_{i=1}^{n} \overline{B_{i c p-1}}}{\overline{B_{p}}}
$$

Keterangan:

$$
\begin{array}{ll}
\mathrm{PBP} & =\text { Waktu pengembalian (tahun) } \\
\mathrm{T} 1 & =\text { Tahun sebelum (tahun) } \\
\mathrm{Ii} & =\text { Total investasi didiskon }(\mathrm{Rp}) \\
\mathrm{B}-1 & =\text { Total benefit discount before } \mathrm{PBP}(\mathrm{Rp}) \\
\mathrm{Bp} & =\text { Total benefit } \mathrm{PBP}(\mathrm{Rp})
\end{array}
$$

Kondisi sensitif dapat disimulasikan dengan melakukan analisis perubahan nilai pada variabel yang berpengaruh. Variabel yang berpengaruh dapat dilakukan dengan penambahan jumlah ataupun penurunan jumlah nilai dari harga yang semula menjadi naik atau turun [9]. Penambahan nilai pada variabel dapat digunakan metode trial and error sehingga akan didapatkan dua titik atau lebih sehingga dapat membentuk suatu garis [4].

Harga batubara berdasarkan Kepmen Energi dan Sumber Daya Mineral yang menentukan dan ditetapkannya harga batubara acuan (HBA) yang dihitung per bulan dengan

\begin{tabular}{|c|c|c|c|c|c|c|}
\hline \multirow[b]{2}{*}{ No. } & \multirow[b]{2}{*}{ Nama dagang } & \multicolumn{4}{|c|}{ Kualitas } & \multirow{2}{*}{$\begin{array}{c}\text { HPB } \\
\text { (US\$/ton) }\end{array}$} \\
\hline & & $\begin{array}{c}\mathrm{CV} \\
(\mathrm{Cal} / \mathrm{Gr})\end{array}$ & $\begin{array}{c}\text { TM } \\
(\%, \text { ar })\end{array}$ & $\begin{array}{c}\text { TS } \\
(\%, \text { ar })\end{array}$ & $\begin{array}{c}\text { Ash } \\
(\%, \text { ar })\end{array}$ & \\
\hline 1 & Gunung Bayan 1 & 7.000 & 10,00 & 1,00 & 15,00 & 63,81 \\
\hline 2 & Prima Coal & 6.700 & 12,00 & 0,60 & 5,00 & 65,27 \\
\hline 3 & Pinang 6150 & 6.200 & 14,00 & 0,60 & 5,50 & 58,97 \\
\hline 4 & Indominco IM_East & 5.700 & 17,50 & 1,63 & 4,80 & 58,99 \\
\hline 5 & Melawan Coal & 5.400 & 22,50 & $\overline{0,40}$ & 5,00 & 48,52 \\
\hline 6 & Envirocoal & 5.000 & 26,00 & 0,10 & 1,20 & 46,27 \\
\hline 7 & Jorong J-1 & 4.400 & 32,00 & 0,25 & 4,15 & 37,23 \\
\hline 8 & Ecocoal & 4.200 & 35,00 & 0,18 & 3,90 & 34,22 \\
\hline
\end{tabular}
perhitungan yang didapatkan dari ICI (Indonesian coal index) dengan nama brand yang telah terdaftar di Ditjen Minerba ditunjukkan di Tabel 1 [11].

Tabel 1. Brand harga patokan batubara di Ditjen Minerba periode Maret 2020

HPB yang ditunjukkan pada Tabel 1 dalam bulan Februari 2020 pada harga batubara acuan (HBA) yaitu $\$ 66,89 /$ ton. HBA dapat ditentukan dengan 4 indexes yaitu Platts59, ICI, GC, dan NEX. Keempat indexes tersebut mempunyai bobot $25 \%$ dari tiap-tiap indexes.
Selanjutnya pada penentuan harga HPB yang ditetapkan menggunakan formulasi yang telah diatur oleh Ditjen Minerba. Harga batubara tersebut adalah harga free on board (FOB) yang ditetapkan menurut peraturan Ditjen Minerba nomor 644K/DJB/2013. Peraturan ini mengatur tentang cara penyesuaian harga patokan batubara melalui pengurangan pada harga awal dikurangi dengan biaya penyesuaian yang terdiri dari biaya transshipment, biaya peninjauan, dan biaya tongkang $[12,13]$.

Biaya transshipment merupakan biaya yang dikeluarkan untuk pemindahan material dari tongkang ke dump truck pembeli. Biaya peninjauan adalah semua biaya tinjauan dari kualitas dan kuantitas batubara. Biaya tongkang adalah semua biaya yang dikeluarkan untuk pemindahan material dari tempat penyimpanan di penjual ke Pelabuhan (Jetty) [12,13].

\section{HASIL DAN PEMBAHASAN}

Perhitungan pada penelitian ini dilakukan berdasarkan metode discounted cash flow dimana pada tahap awal dicari aliran kas terlebih dahulu dan selanjutnya di analisis berdasarkan parameter investasi. Perhitungan aliran kas didapatkan dari perhitungan pendapatan penjualan batubara, royalti, depresiasi, biaya operasional, biaya kepemilikan alat, biaya kapital, dan pajak, kemudian dibuat dalam bentuk aliran kas.

\section{Biaya kapital (capital cost)}

Dalam penelitian ini investasi yang dilakukan berupa investasi alat berat dimulai dari kegiatan pengupasan menggunakan excavator backhoe, dilanjutkan dengan kegiatan pengangkutan menggunakan dump truck dan untuk alat pendukung utama berupa bulldozer,

\begin{tabular}{|c|c|}
\hline Uraian & Harga Alat (Rp) \\
\hline \multicolumn{2}{|l|}{ A. Kegiatan Penggalian (Pengupasan) } \\
\hline Excavator Backhoe Kobelco SK-330- 2 unit & $4.600 .000 .000,00$ \\
\hline Excavator Backhoe Hitachi PC-350H & $2.500 .000 .000,00$ \\
\hline Excavator Backhoe Komatsu PC-300 & $1.800 .000 .000,00$ \\
\hline \multicolumn{2}{|l|}{ B. Kegiatan Pengangkutan } \\
\hline Dump Truck Mitsubishi 220PS 6x4 HD & $1.000 .000 .000,00$ \\
\hline Dump Truck Man TGS $40-4$ unit & $7.200 .000 .000,00$ \\
\hline Dump Truck Hino 500 FM 260-15 unit & $15.000 .000 .000,00$ \\
\hline \multicolumn{2}{|l|}{ C. Kegiatan Pendukung } \\
\hline Bulldozer Caterpillar D7G & $1.500 .000 .000,00$ \\
\hline Bulldozer Komatsu D85E - 2 unit & $2.600 .000 .000,00$ \\
\hline Tower lamp - 5 unit & $500.000 .000,00$ \\
\hline Grader Caterpillar 120 & $1.100 .000 .000,00$ \\
\hline Compactor Sakai SV521D & $800.000 .000,00$ \\
\hline Biaya kapital Keseluruhan & $38.600 .000 .000,00$ \\
\hline
\end{tabular}
compactor, grader, dan tower lamp. Adapun biaya kapital yang digunakan oleh perusahaan PT. CTSP berdasarkan kegiatan penambangannya ditunjukkan pada Tabel 2.

Tabel 2. Biaya kapital 
Biaya Operasional

Perhitungan biaya dalam memproduksi batubara di PT. CTSP dapat berupa biaya bahan bakar minyak berdasarkan dari data perhitungan konsumsi bahan bakar, filter, dan oli (pelumas) dari penggunaan selama 1 tahun. Kemudian perhitungan ban dan undercarriage dapat dihitung berdasarkan umur ekonomis ban/crawler. Biaya perbaikan didapatkan dari data perusahaan, dan biaya tenaga kerja mengikuti UMP. Biaya operasional ditunjukan pada Tabel 3.

Tabel 3. Biaya operasional

\begin{tabular}{|l|l|r|}
\hline No. & \multicolumn{1}{|c|}{ Komponen biaya } & \multicolumn{1}{c|}{ Jumlah (Rp/tahun) } \\
\hline 1. & Fuel $(\mathrm{BBM})$ & $34.709 .384 .773,26$ \\
\hline 2. & Oli dan pelumas mesin & $1.335 .776 .516,10$ \\
\hline 3. & Ban & $1.676 .717 .280,00$ \\
\hline 4. & Undercarriage cost & $966.540 .000,00$ \\
\hline 5. & Reparasi (maintanance) & $3.898 .880 .316,00$ \\
\hline 6. & Biaya tenaga kerja & $5.746 .724 .037,00$ \\
\hline & Biaya Keseluruhan & $48.334 .022 .981,10$ \\
\hline
\end{tabular}

\section{Biaya Tetap (Fixed Cost)}

Metode penyusutan pada penelitian adalah metode garis lurus (straight line method) yang dipilih berdasarkan peraturan pemerintah dan kontrak karya generasi ke 7 . Berdasarkan kontrak karya batubara, metode ini diasumsikan dengan nilai pada akhir proyek dianggap tersisa $10 \%$ dari harga pembelian awal. Kemudian untuk biaya penyusutan ditetapkan berdasarkan $\mathrm{UU} \mathrm{PPh}$ pasal 11 dimana dalam usaha pertambangan hanya dikenakan $6,25 \%$ pertahun. Sedangkan perhitungan bunga dapat mengikuti suku bunga deposito yaitu sebesar $6 \%$. Kemudian untuk perhitungan pajak yang dikenakan pada alat berat sebesar $1,5 \%$ [4].

Biaya asuransi yang dikeluarkan berdasarkan premi yaitu $1 \%$ dari harga alat, dan untuk perawatan gudang penyimpanan peralatan yaitu sebesar 1\% [5]. Berikut ini adalah total owning cost ditunjukkan dalam Tabel 4.

Tabel 4. Fixed Cost

\begin{tabular}{|c|r|}
\hline \multicolumn{1}{|c|}{ Rincian } & $\begin{array}{c}\text { Jumlah } \\
\text { (Rp/tahun) }\end{array}$ \\
\hline A. Kegiatan Pengupasan & $10.631 .772,32$ \\
\hline 1. 1 unit Excavator Backhoe Hitachi PC-350H & $19.562 .461,06$ \\
\hline 2. 2 unit Excavator Backhoe Kobelco SK-330 & $7.654 .876,07$ \\
\hline 3. 1 unit Excavator Backhoe Komatsu PC-300 & \\
\hline B. Kegiatan Pengangkutan & $30.619 .504,26$ \\
\hline 1. 4 unit Dump Truck Man TGS 40 & $63.790 .633,88$ \\
\hline 2.15 unit Dump Truck Hino 500 FM-260TI/JB & $4.252 .708,93$ \\
\hline 3.1 unit Dump Truck Mitsubishi 220PS 6x4 HD & $6.379 .063,39$ \\
\hline C. Kegiatan Pendukung & $11.057 .043,20$ \\
\hline 1.1 unit Bulldozer Caterpillar D7G & $3.402 .167,15$ \\
\hline 2. 2 unit Bulldozer Komatsu D85E & $4.677 .979,82$ \\
\hline 3.1 unit Compactor Sakai SV521D & $2.126 .354,47$ \\
\hline 4.1 unit Grader Caterpillar 120 & $164.154 .564,55$ \\
\hline 5. 5 unit Tower lamp & \\
\hline Total biaya (Rp/tahun) & \\
\hline
\end{tabular}

Cash Flow

Cash flow atau aliran kas yang didapatkan dari perhitungan selawa waktu periode tertentu yang dapat mengestimasikan aliran kas kedepan. Dalam perhitungan harga batubara yang digunakan telah dilakukan penyesuaian berdasarkan peraturan Ditjen Minerba No. 644K/DJB/2013 [11]. Cash flow ditunjukkan didalam Tabel 5.

Tabel 5. Cash flow

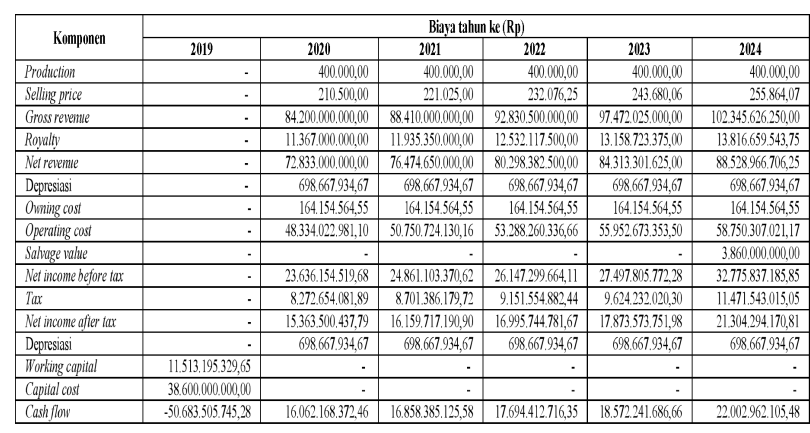

Dari cash flow yang telah didapatkan maka selanjutnya dapat dihitung parameter ekonomi yang berupa net present value (NPV), gross benefit cost ratio (Gross $\mathrm{B} / \mathrm{C})$, rate of return (IRR), present value rasio (PVR), payback period (PBP). Perhitungan ini menggunakan Pers.(1-5). Berdasarkan perhitungan tersebut didapatkan hasil yang ditunjukkan dalam Tabel 6 .

Tabel 6. Parameter Investasi

\begin{tabular}{|c|l|r|}
\hline No. & \multicolumn{1}{|c|}{ Parameter } & \multicolumn{1}{|c|}{ Nilai } \\
\hline 1 & NPV & Rp 17.492.288.670,07 \\
\hline 2 & Gross B/C & 1,35 \\
\hline 3 & IRR & $22,07 \%$ \\
\hline 4 & PVR & 0,35 \\
\hline 5 & PBP & 3,70 Tahun \\
\hline
\end{tabular}

Tingkat Keekonomian Harga Batubara dengan Biaya Operasional

Tingkat keekonomian kegiatan penambangan pada penelitian ini dianalisis berdasarkan nilai NPV, PVR, Gross B/C, IRR dan PBP yang dihitung pada saat harga jual batubara dan biaya operasional kegiatan penambangan turun $10 \%$, tetap dan meningkat sebesar $10 \%$.

Hasil perubahan net present value (NPV) pada saat harga jual batubara dan biaya operasi turun, tetap dan meningkat, ditunjukan pada Gambar 1 dan Tabel 7. 
Tabel 7. NPV harga jual batubara dan biaya operasi

\begin{tabular}{|c|r|r|r|}
\hline Keterangan & \multicolumn{1}{|c|}{ Harga batubara $-10 \%$} & \multicolumn{1}{|c|}{ Harga batubara tetap } & \multicolumn{1}{|c|}{ Harga batubara $+10 \%$} \\
\hline Biaya operasi $-10 \%$ & $\mathrm{Rp} 12.091 .098 .631,88$ & $\mathrm{Rp} 31.740 .599 .550,82$ & $\mathrm{Rp} 51.390 .100 .469,76$ \\
\hline Biaya operasi Tetap & $\mathrm{Rp}-2.157 .212 .248,88$ & $\mathrm{Rp} 17.492 .288 .670,07$ & $\mathrm{Rp} 37.141 .789 .589,01$ \\
\hline Biaya operasi $+10 \%$ & $\mathrm{Rp}-16.405 .523 .129,63$ & $\mathrm{Rp} 3.243 .977 .789,31$ & $\mathrm{Rp} 22.893 .478 .708,26$ \\
\hline
\end{tabular}

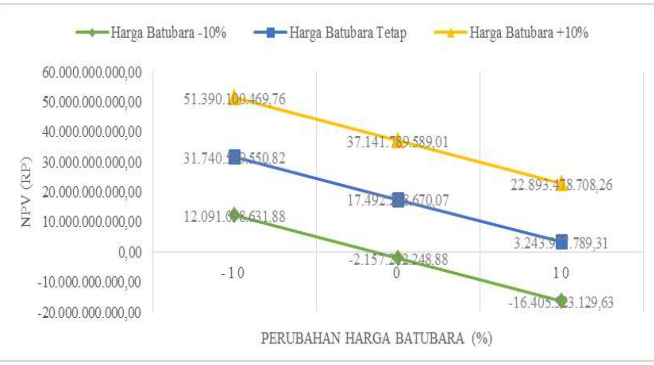

Gambar 1. NPV harga jual batubara dan biaya operasi

Hasil yang ditunjukkan dalam Tabel 7 dan Gambar 1 memperlihatkan bahwa pada kondisi harga jual naik sebesar $10 \%$ dan biaya operasional turun $10 \%$, nilai NPV semakin besar. Sebaliknya pada kondisi harga jual turun sebesar $10 \%$ dan biaya operasional naik sebesar $10 \%$ maka nilai NPV menjadi turun, yaitu Rp.16.405.523.129,63. Angka ini menunjukan bahwa pada kondisi ini kegiatan penambangan tidak layak untuk dilaksanakan.

Hasil perhitungan PVR pada saat perubahan harga jual dan biaya operasi, ditunjukan pada Tabel 8 .

Tabel 8. PVR harga jual batubara dan biaya operasi

\begin{tabular}{|c|r|r|r|}
\hline Keterangan & Harga batubara $-10 \%$ & Harga batubara tetap & Harga batubara $+10 \%$ \\
\hline Biaya operasi $-10 \%$ & 0,24 & 0,64 & 1,04 \\
\hline Biaya operasi Tetap & $-0,04$ & 0,35 & 0,73 \\
\hline Biaya operasi $+10 \%$ & $-0,32$ & 0,06 & 0,44 \\
\hline
\end{tabular}

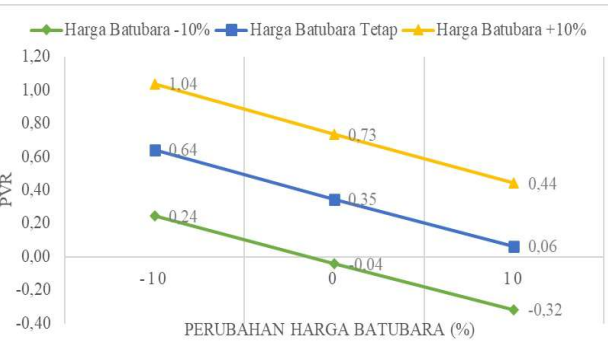

Gambar 2. PVR harga batubara dan biaya operasi

Berdasarkan Gambar 2 dan Tabel 8 terlihat bahwa tingkat ekonomi yang rendah berada pada harga jual batubara turun dan biaya operasional naik dimana diperoleh nilai PVR sebesar -0,32. Angka ini menunjukan bahwa pada kondisi ini tidak layak untuk ditambang. Sedangkan, pada tingkat ekonomi tinggi ditunjukkan pada harga jual batubara naik dan biaya operasional turun yang dinyatakan layak untuk dilakukan penambangan dengan nilai PVR 1,04.

Hasil perhitungan Gross B/C pada saat perubahan harga jual dan biaya operasi, ditunjukan pada Tabel 9.

Tabel 9. Gross B/C harga batubara dan biaya operasi

\begin{tabular}{|c|r|r|r|}
\hline Keterangan & Harga batubara & Harga batubara & Harga batubara \\
& $10 \%$ & tetap & $+10 \%$ \\
\hline Biaya operasi $-10 \%$ & 1,24 & 1,64 & 2,04 \\
\hline Biaya operasi Tetap & 0,96 & 1,35 & 1,73 \\
\hline Biaya operasi $+10 \%$ & 0,68 & 1,06 & 1,44 \\
\hline
\end{tabular}

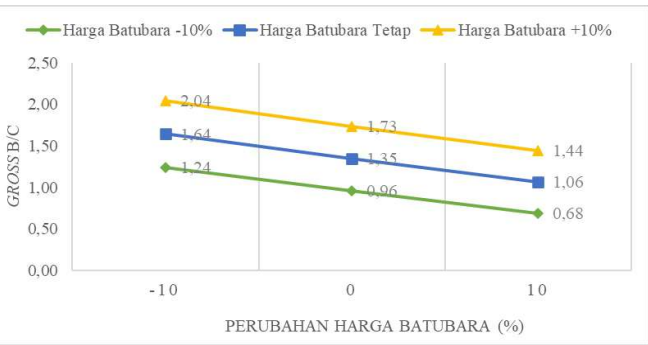

Gambar 3. Gross B/C harga batubara dan biaya operasi

Hasil perhitungan Gross B/C yang ditunjukkan pada Gambar 3 dan Tabel 9 memperlihatkan bahwa tingkat ekonomi yang rendah berada pada harga jual batubara turun dan biaya operasional naik dengan nilai Gross B/C 0,68. Pada kondisi ini kegiatan penambangan tidak layak untuk ditambang. Sedangkan, pada tingkat ekonomi tinggi terlihat pada harga jual batubara naik dan biaya operasional turun yang dinyatakan layak untuk dilakukan penambangan dengan nilai Gross B/C 1,44.

Hasil perhitungan Gross B/C pada saat perubahan harga jual dan biaya operasi, ditunjukan pada Tabel 9.

Tabel 10. IRR harga jual batubara dan biaya operasi

\begin{tabular}{|c|r|r|c|}
\hline Keterangan & $\begin{array}{c}\text { Harga } \\
\text { batubara }-10 \%\end{array}$ & $\begin{array}{c}\text { Harga batubara } \\
\text { tetap }\end{array}$ & $\begin{array}{c}\text { Harga batubara } \\
+10 \%\end{array}$ \\
\hline Biaya operasi $-10 \%$ & $18,67 \%$ & $31,59 \%$ & $43,57 \%$ \\
\hline Biaya operasi Tetap & $8,41 \%$ & $22,07 \%$ & $34,42 \%$ \\
\hline Biaya operasi $+10 \%$ & $-2,60 \%$ & $12,29 \%$ & $25,23 \%$ \\
\hline
\end{tabular}

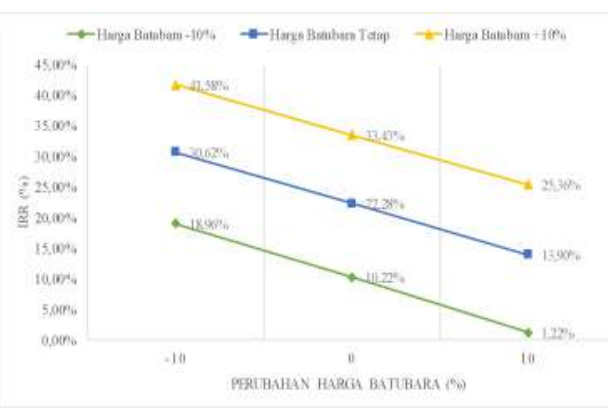

Gambar 4. IRR harga jual dan biaya operasi proyek penambangan 
Dari perhitungan IRR yang ditunjukkan pada Gambar 4 dan Tabel 10 terlihat bahwa tingkat ekonomi yang rendah berada pada harga jual batubara turun dan biaya operasional naik yang menunjukan bahwa tidak layak untuk ditambang dengan nilai IRR -2,60\%. Sedangkan, pada tingkat ekonomi tinggi terlihat pada harga jual batubara naik dan biaya operasional turun yang menunjukan layak untuk dilakukan penambangan dengan nilai IRR 43,57\%.

Perhitungan cepat lambatnya pengembalian modal dapat ditunjukkan pada Gambar 5 dan Tabel 11.

Tabel 11. PBP harga jual batubara dan biaya operasi penambangan

\begin{tabular}{|c|c|c|c|}
\hline Keterangan & $\begin{array}{c}\text { Harga batubara - } \\
10 \%\end{array}$ & $\begin{array}{c}\text { Harga batubara } \\
\text { tetap }\end{array}$ & $\begin{array}{c}\text { Harga batubara } \\
+10 \%\end{array}$ \\
\hline Biaya operasi $-10 \%$ & 4,03 & 2,96 & 2,35 \\
\hline Biaya operasi Tetap & 5,21 & 3,70 & 2,80 \\
\hline Biaya operasi $+10 \%$ & 7,13 & 4,71 & 3,42 \\
\hline
\end{tabular}

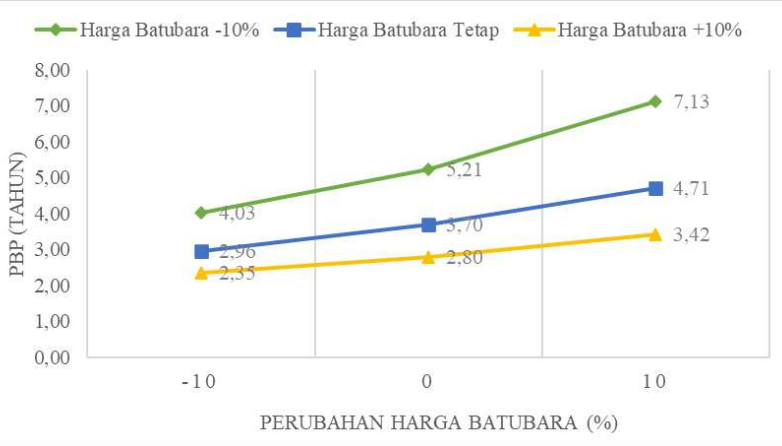

Gambar 5. PBP harga batubara dan biaya operasi penambangan

Dari Gambar 5 dan Tabel 11 terlihat bahwa waktu pengembalian tercepat berada pada harga jual batubara naik dan biaya operasional yang turun. Pada perhitungan untuk waktu pengembalian terlama adalah pada saat harga jual batubara rendah dan biaya operasional tinggi dengan waktu pengembalian berada diluar waktu proyek penambangan sehingga tidak layak untuk dilakukan penambangan.

Pengaruh Naik Turunnya Biaya Kapital dan Umur Proyek Penambangan

Penelitian ini menunjukan bahwa nilai paling rendah diperoleh pada saat naiknya biaya kapital $10 \%$, dan turunnya umur proyek. Pada kondisi ini diperoleh nilai NPV Rp 1.855.229.163,77 yang menunjukkan nilai positif (+). Nilai PVR 0,03 menunjukkan nilai kriteria di atas 0. Nilai Gross B/C 1,03 menunjukkan nilai kriteria di atas 1. Nilai IRR 11,49\% menunjukkan nilai IRR di atas dari discount rate yang digunakan, dan nilai PBP 4 tahun yang artinya tidak melebihi umur proyek tambang.

Tabel 12. Biaya kapital dan umur proyek terhadap NPV

\begin{tabular}{|c|c|c|c|}
\hline Keterangan & Biaya Kapital - $10 \%$ & Biaya Kapital tetap & Biaya Kapital $+10 \%$ \\
\hline Umur Proyek - $10 \%$ & Rp 9.232.493.011,87 & Rp 5.543.861.087,82 & Rp 1.855.229.163,77 \\
\hline Umur Proyek Tetap & Rp 21.352.288.670,07 & Rp 17.492.288.670,07 & Rp 13.632.288.670,07 \\
\hline Umur Proyek $+10 \%$ & Rp 32.760.797.067,60 & Rp 28.900.797.067,60 & Rp 25.040.797.067,60 \\
\hline
\end{tabular}

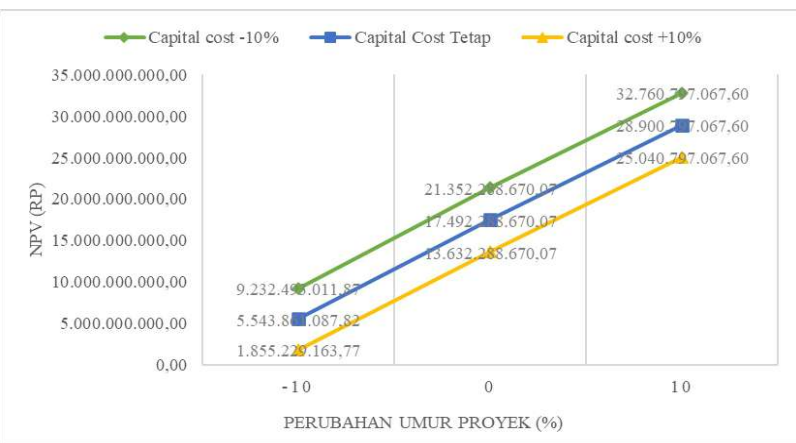

Gambar 6. Grafik NPV biaya kapital dan umur proyek

Hasil yang ditunjukkan dalam Gambar 6 dan Tabel 12 memperlihatkan bahwa nilai NPV semakin besar saat biaya kapital turun $10 \%$ dan umur proyek naik $10 \%$ yaitu sebesar Rp 32.760.797.067,60. Penelitian ini juga memperlihatkan nilai akan semakin mengecil saat umur proyek turun sebesar $10 \%$ dan biaya kapital naik sebesar $10 \%$ yaitu dengan NPV sebesar Rp 1.855.229.163,77. Nilai ini menyatakan bahwa kegiatan penambangan layak untuk dilaksanakan dengan nilai ekonomis yang lebih rendah.

Tabel 13. Biaya kapital dan umur proyek terhadap PVR

\begin{tabular}{|l|r|r|r|}
\hline \multicolumn{1}{|c|}{ Keterangan } & $\begin{array}{c}\text { Biaya Kapital } \\
-10 \%\end{array}$ & $\begin{array}{c}\text { Biaya Kapital } \\
\text { tetap }\end{array}$ & \multicolumn{2}{c|}{$\begin{array}{c}\text { Biaya Kapital } \\
+10 \%\end{array}$} \\
\hline $\begin{array}{l}\text { Umur Proyek } \\
-10 \%\end{array}$ & 0,20 & 0,11 & 0,03 \\
\hline $\begin{array}{l}\text { Umur Proyek } \\
\text { Tetap }\end{array}$ & 0,46 & 0,35 & 0,25 \\
\hline $\begin{array}{l}\text { Umur Proyek } \\
+10 \%\end{array}$ & 0,70 & 0,57 & 0,46 \\
\hline
\end{tabular}

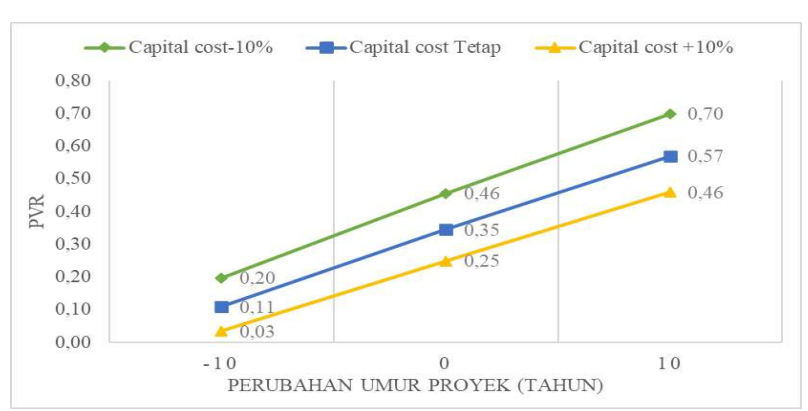

Gambar 7. Grafik PVR biaya kapital dan umur proyek 
Hasil perhitungan PVR pada Gambar 7 dan Tabel 13 menunjukan bahwa tingkat ekonomi yang rendah berada pada biaya kapital yang naik sebesar $10 \%$ dan umur proyek yang turun sebesar $10 \%$ dengan nilai PVR sebesar 0,03. Hal ini menunjukan bahwa kegiatan penambangan masih layak untuk dilakukan. Sedangkan, pada tingkat ekonomi tinggi terlihat pada biaya kapital turun sebesar $10 \%$ dan umur proyek naik sebesar $10 \%$ diperoleh nilai PVR sebesar 0,70. Hal ini menunjukan kegiatan penambangan layak untuk dilaksanakan.

Tabel 14. Gross B/C perubahan Biaya kapital dan umur Proyek

\begin{tabular}{|l|r|r|r|}
\hline \multicolumn{1}{|c|}{ Keterangan } & \multicolumn{1}{|c|}{$\begin{array}{c}\text { Biaya Kapital } \\
-10 \%\end{array}$} & $\begin{array}{c}\text { Biaya Kapital } \\
\text { tetap }\end{array}$ & $\begin{array}{c}\text { Biaya Kapital } \\
+10 \%\end{array}$ \\
\hline $\begin{array}{l}\text { Umur Proyek - } \\
10 \%\end{array}$ & 1,20 & 1,11 & 1,03 \\
\hline $\begin{array}{l}\text { Umur Proyek } \\
\text { Tetap }\end{array}$ & 1,46 & 1,35 & 1,25 \\
\hline $\begin{array}{l}\text { Umur Proyek } \\
+10 \%\end{array}$ & 1,70 & 1,57 & 1,46 \\
\hline
\end{tabular}

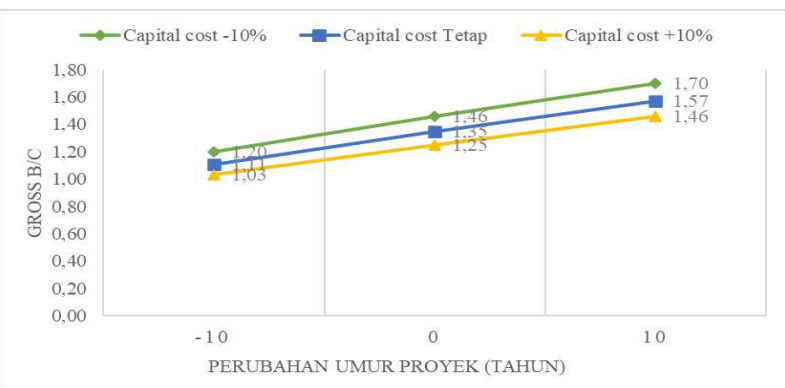

Gambar 8. Gross B/C biaya kapital dan umur proyek penambangan

Hasil perhitungan Gross B/C pada Gambar 8 dan Tabel 14 menunjukan bahwa tingkat ekonomi yang rendah berada pada biaya kapital yang meningkat sebesar $10 \%$ dan umur proyek yang turun sebesar 10\%. Dari hasil ini menunjukan bahwa masih layak untuk dilakukan kegiatan penambangan tetapi dengan nilai Gross B/C 1,03. Sedangkan, pada tingkat ekonomi tinggi terlihat pada saat biaya kapital turun $10 \%$ dan umur proyek naik yang menunjukan layak untuk dilakukan penambangan dengan nilai Gross B/C 1,70.

Nilai internal rate of return (IRR) yang diperoleh pada pengaruh biaya kapital dan umur proyek ditunjukkan dalam Tabel 15 dan Gambar 9.

Tabel 15. IRR perubahan biaya kapital dan umur proyek

\begin{tabular}{|c|r|r|r|}
\hline Uraian & $\begin{array}{c}\text { Biaya Kapital - } \\
10 \%\end{array}$ & $\begin{array}{c}\text { Biaya Kapital } \\
\text { tetap }\end{array}$ & $\begin{array}{c}\text { Biaya Kapital } \\
+10 \%\end{array}$ \\
\hline Umur Proyek $-10 \%$ & $17,62 \%$ & $14,05 \%$ & $10,91 \%$ \\
\hline Umur Proyek Tetap & $25,78 \%$ & $22,28 \%$ & $19,19 \%$ \\
\hline Umur Proyek $+10 \%$ & $30,82 \%$ & $27,50 \%$ & $24,57 \%$ \\
\hline
\end{tabular}

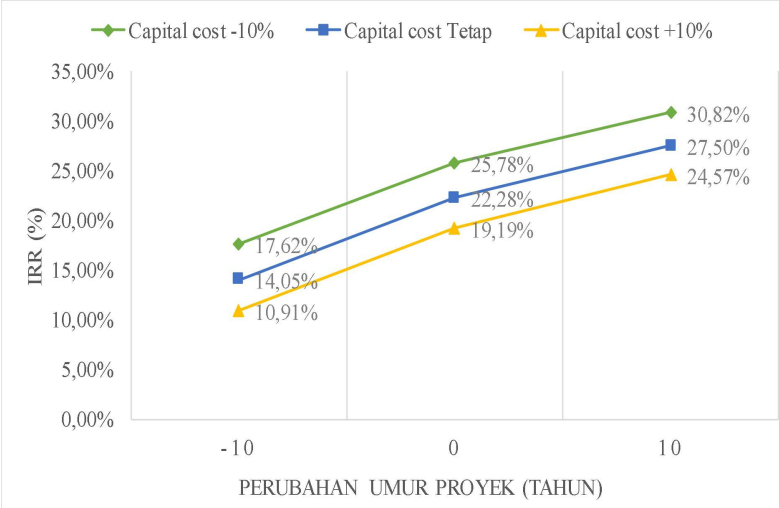

Gambar 9. IRR biaya kapital dan umur proyek penambangan

Perhitungan IRR pada Gambar 9 dan Tabel 15 menunjukan bahwa tingkat ekonomi yang rendah berada pada biaya kapital naik $10 \%$ dan umur proyek turun $10 \%$. Pada kondisi ini menunjukan kegiatan penambangan masih layak untuk dilakukan tetapi dengan nilai IRR $10,91 \%$. Sedangkan, pada tingkat ekonomi tinggi terlihat pada saat biaya kapital turun $10 \%$ dan umur proyek naik $10 \%$ yang menunjukan layak untuk dilakukan penambangan dengan nilai IRR 30,82\%.

Berdasarkan cepat lambatnya waktu pengembalian modal terhadap biaya kapital dan umur proyek yang ditunjukkan pada Gambar 10 dan Tabel 16.

Tabel 16. PBP perubahan biaya kapital dan umur proyek

\begin{tabular}{|c|c|c|c|}
\hline Uraian & $\begin{array}{c}\text { Biaya Kapital - } \\
10 \%\end{array}$ & $\begin{array}{c}\text { Biaya Kapital } \\
\text { tetap }\end{array}$ & $\begin{array}{c}\text { Biaya Kapital } \\
+10 \%\end{array}$ \\
\hline $\begin{array}{l}\text { Umur Proyek - } \\
10 \%\end{array}$ & 3,35 & 3,61 & 3,87 \\
\hline $\begin{array}{l}\text { Umur Proyek } \\
\text { Tetap }\end{array}$ & 3,39 & 3,70 & 4,00 \\
\hline $\begin{array}{l}\text { Umur Proyek } \\
+10 \%\end{array}$ & 3,39 & 3,70 & 4,00 \\
\hline
\end{tabular}

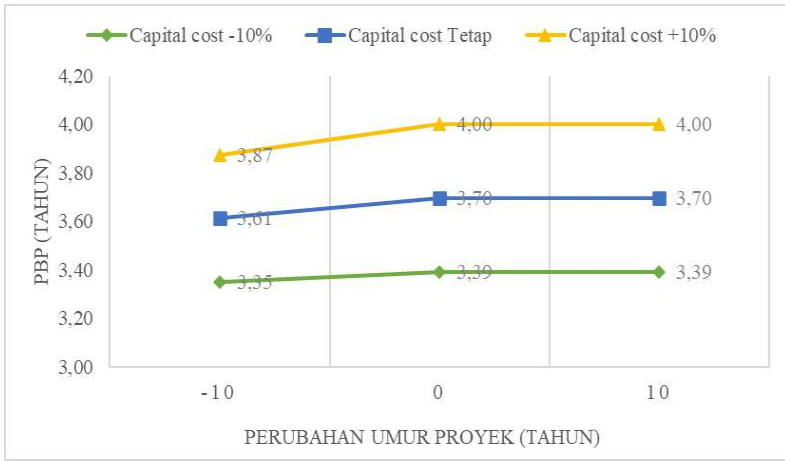

Gambar 10. Grafik PBP perubahan biaya kapital dan umur proyek 
Hasil perhitungan dari Gambar 10 dan Tabel 16 terlihat bahwa umur proyek yang naik tidak berpengaruh pada parameter ini. Hasil perhitungan ini menunjukan bahwa jika biaya kapital yang naik maka waktu pengembalian modal pun akan naik tetapi kenaikkannya tidak signifikan dan masih dinyatakan layak.

\section{KESIMPULAN}

Berdasarkan perhitungan dari metode discounted cash flow, kegiatan penambangan di PT Citra Tobindo Sukses Peerkasa layak untuk dilaksanakan dengan nilai NPV Rp 17.492.288.670,07, IRR 22,07\%, PBP 3,70 tahun, PVR 0,35, dan Gross B/C 1,35.

Hasil penelitian menyatakan bahwa tingkat ekonomi yang tinggi berada pada harga batubara naik $10 \%$ dan biaya operasi turun $10 \%$ dan disimpulkan layak untuk dilakukan penambangan. Pada tingkat ekonomi rendah dengan harga batubara turun $10 \%$ dan biaya operasi naik $10 \%$, kegiatan penambangan tidak layak untuk dilakukan.

Hasil penelitian menunjukan bahwa tingkat ekonomi yang tinggi berada pada umur proyek naik $10 \%$ dan biaya kapital turun $10 \%$ dan disimpulkan bahwa layak untuk dilakukan penambangan. Pada tingkat ekonomi rendah dengan biaya kapital naik $10 \%$ dan umur proyek turun $10 \%$ disimpulkan bahwa tidak layak untuk dilakukan penambangan.

\section{UCAPAN TERIMA KASIH}

Penulis berterima kasih kepada Bapak Andi Syahbudi, S.T. selaku ketua teknik tambang dan Bapak Ahmad Fudel, S.T. selaku mine planner di PT. Citra Tobindo Sukses Perkasa yang sudah memberikan waktu, pikiran, kesempatan, mendukung dalam pengambilan data, mengizinkan dalam menggunakan data serta dapat diajak berdiskusi dalam penelitian ini.

\section{DAFTAR PUSTAKA}

[1] Kementerian Energi dan Sumber Daya Mineral. (2019). Peraturan Menteri Energi dan Sumber Daya Mineral No. 261 K/30/MEM/2019 Tentang pemenuhan kebutuhan batubara dalam negeri tahun 2020. Jakarta: Kementerian ESDM.

[2] Suryawan, K. (2019). Manajemen Alat Berat. Yogyakarta: Deepublish.

[3] Arif, Irwandy. (2014). Batubara Indonesia. Bandung: Fakultas Teknik, Institut Teknologi Bandung.

[4] Blank, Leland. \& Tarquin, Anthony. (2012). Engineering Economy, seventh edition. America: Elizabeth A. Jones.

[5] Ondo Immanuel S. (2019). Analisis Investasi dan Kelayakan Ekonomi pada Kegiatan
Penambangan Batubara PT. Pinggan Wahana Pratama Job Site PT. Singlurus Pratama, Kecamatan Samboja, Kabupaten Kutai Kartanegara, Provinsi Kalimantan Timur. Jurnal Teknologi Mineral. 7(1), 3049.

[6] M. Rezky A.S. (2018). Analisis Capital Budgeting Untuk Menilai Kelayakan Investasi dalam Usaha Penambangan Batubara pada PT. Tuah Globe Mining Provinsi Kalimantan Tengah. Jurnal Geomine, 6(1), 1-5.

[7] Marthin, S. (2018). Analisis Keekonomisan Pemilihan Alat Gali Muat Untuk Pembongkaran Overburden di Tambang Air Laya PT. Bukit Asam (Persero), Tbk. Jurnal Pertambangan, 2(3), 34-38.

[8] Titoe, D. (2018). Kajian Analisis Ekonomi Tambang Menggunakan Metode Discounted Cash Flow pada Pertambangan Batubara PT Pasir Prima Coal Indonesia, Desa Mentawir, Kecamatan Sepaku, Kabupaten Penajam Paser Utara, Provinsi Kalimantan Timur. Jurnal Teknik Pertambangan, 4(2), 411-417.

[9] Haq N. (2018). Modeling Valuation, Risk, and Decision in Mining Projects. Jakarta: Fira Publishing.

[10] Damodaran, Aswath. (2012). Investment Valuation Tools and Techniques for Determining the Value of Any Asset. New Jersey: John Wiley $\&$ Sons, Inc.

[11] Kementerian Energi dan Sumber Daya Mineral. (2020). Keputusan Menteri Energi dan Sumber Daya Mineral Nomor 43 K/32/MEM/2020 tentang Harga Mineral Logam Acuan dan Harga Batubara Acuan Untuk Bulan Februari Tahun 2020. Jakarta: Kementerian ESDM.

[12] Pemerintah Indonesia. (2013). Peraturan Direktur Jendral Mineral dan Batubara nomor $644 K / D J B / 2013$ tentang tata cara penetapan besaran biaya penyesuaian harga patokan batubara. Jakarta: Sekretariat Negara.

[13] Ijang, Bambang. (2018). Analisis Penentuan Harga Jual Batubara PT Berau Coal untuk Pembangkit Listrik Tenaga Uap Mulut Tambang Lati. Jurnal Teknologi Mineral dan Batubara. 14(2), 141-157. 